Article

\title{
Relative Concerns and Delays in Bargaining with Private Information
}

\author{
Ana Mauleon ${ }^{1,2}$ and Vincent Vannetelbosch ${ }^{1,2, *}$ \\ ${ }^{1}$ CORE, University of Louvain, 34 Voie du Roman Pays, 1348 Louvain-la-Neuve, Belgium; \\ E-Mail:mauleon@fusl.ac.be \\ ${ }^{2}$ CEREC, Saint-Louis University, 43 Boulevard du Jardin Botanique, 1000 Brussels, Belgium \\ * Author to whom correspondence should be addressed; E-Mail: vincent.vannetelbosch@uclouvain.be; \\ Tel.: +32-10-474142; Fax: +32-10-474301.
}

Received: 28 March 2013; in revised form: 27 May 2013 / Accepted: 13 June 2013 /

Published: 27 June 2013

\begin{abstract}
We consider Rubinstein's two-person alternating-offer bargaining model with two-sided incomplete information. We investigate the effects of one party having relative concerns about the bargaining outcome and the delay in reaching an agreement. We find that facing an opponent with stronger relative concerns only hurts the bargainer when she is stronger than her opponent. In addition, we show that an increase of one party's relative concerns will decrease the maximum delay in reaching an agreement.
\end{abstract}

Keywords: relative concerns; alternating-offer bargaining; private information; maximal delays

\section{Introduction}

A two-person bargaining situation involves two individuals who have the possibility of concluding a mutually beneficial agreement, but there is a conflict of interests about which agreement to conclude, and no agreement can be imposed on any individual without her approval. One bargaining procedure dominates the literature on noncooperative bargaining models: Rubinstein's alternating-offer bargaining procedure [1]. In Rubinstein's model, the players alternate in making proposals, with no exogenous bound on the length of time that they may bargain. They also have time preferences: among agreements reached at the same time players prefer larger shares of the cake and prefer to obtain any given share of the cake sooner rather than later. Under mild conditions on the time preferences of the players, 
Rubinstein has shown that the alternating-offer bargaining game with complete information yields a unique subgame perfect equilibrium (SPE). In this SPE, agreement is reached without delay and the less impatient player obtains a larger share of the cake.

Rubinstein's model assumes that players have purely selfish preferences. Experimental and field evidence conflicts with the hypothesis of selfishness and suggests that players have interdependent preferences. ${ }^{1}$ In other words, when players bargain over the division of a cake they are also influenced by relative share considerations. For instance, Brown, Gardner, Oswald and Qian [5], using data collected from 16,000 British workers, have found evidence that the welfare of a worker is not solely determined by his or her material circumstances, but also depends on his or her relative wage and the rank-ordered position of his or her wage within a comparison set. ${ }^{2}$

The purpose of this paper is to provide a theoretical study of how relative concerns will affect the outcome of Rubinstein's alternating-offer model when players have either complete information or private information. One bargainer has preferences over relative payoffs (fairness) as well as absolute payoffs (pecuniary). Her utility increases as the absolute payoff increases, but it diminishes as her relative payoff deviates from the fair standard. The other bargainer is selfish and simply maximizes his own payoff. We find that, under complete information, facing an opponent having stronger relative concerns only hurts the bargainer when she is stronger than her opponent. Once incomplete information is added into the bargaining, agreement may be reached with delay. We show that an increase of one party's relative concerns decreases the delay in reaching an agreement. Intuitively, when the bargainer who has relative concerns cares more about payoff inequality, she becomes more inclined to concede and to rapidly accept a smaller share of the surplus than before, since this loss is compensated by the increased utility due to less envy and compassion. In addition, when the selfish bargainer faces an opponent who dislikes more payoff inequality, then the payoffs he could obtain become closer to the equitable payoff division. Hence, this selfish player will also be more inclined to rapidly reach an agreement.

The paper is organized as follows. In Section 2 we introduce the bargaining model and solve it under complete information. In Section 3 we consider the bargaining with private information. In Section 4 we characterize the maximal delay in reaching an agreement. In Section 5 we conclude.

\section{Model}

Two players $i(i=1,2)$ are bargaining over the division of a cake of size one. These two players must agree on an allocation from the set $X \equiv\left\{\left(x_{1}, x_{2}\right) \in \mathbb{R}^{2} \mid x_{1}, x_{2} \geq 0, x_{1}+x_{2} \leq 1\right\}$ where $x_{i}$ is player $i$ 's share, for $i=1,2$. Player 1 cares about her own share and, in addition, would like to reduce the inequality in shares between the two players. Formally, the objective of player 1 is to maximize a utility function similar to Bolton and Ockenfels' [7] model of inequality aversion:

\footnotetext{
${ }^{1}$ See De Bruyn and Bolton [2] for experimental evidence on two-person bargaining. Sobel [3] has provided an excellent survey of models that have been devised to explain behavior inconsistent with purely selfish maximization. In addition, Hopkins [4] has provided a survey of different theoretical models of relative concerns and their relation to inequality.

${ }^{2}$ Clark and Oswald [6], using data on 5,000 Bristish workers, have found evidence that workers' reported satisfaction levels are inversely related to their comparison wage rates.
} 


$$
u_{1}\left(x_{1}, x_{2}\right)=x_{1}-\gamma\left(\frac{x_{1}+x_{2}}{2}-x_{1}\right)^{2}
$$

where the parameter $\gamma, 1 \geq \gamma>0$, captures the loss from inequality if player 1's share is below or above an equitable allocation. ${ }^{3}$ Player 2 is a purely selfish player who simply maximizes his share of the cake: $u_{2}\left(x_{1}, x_{2}\right)=x_{2}{ }^{4}$

We adopt Rubinstein's alternating-offer bargaining procedure. Player 1 calls (offers/accepts) in evennumbered periods and player 2 calls in odd-numbered periods. Let $n \in \mathbb{N}$ be the period at which an offer is made. The game starts at $n=0$ and ends when one of the players accepts the opponent's previous offer. Note that an agreement may be reached as early as in period $n=1$. The length of each period is $\Delta$. No limit is placed on the time that may be expended in bargaining and perpetual disagreement is a possible outcome. Both players are assumed to be impatient and they have time preferences with constant discount rates. That is, player $i$ is indifferent between receiving $u_{i}\left(x_{1}, x_{2}\right) \cdot \exp \left(-r_{i} \Delta\right)$ today and $u_{i}\left(x_{1}, x_{2}\right)$ tomorrow, where $r_{i}>0$ is player $i$ 's discount rate. To capture the notion that the time it takes to come to terms is small relative to the length of the contract, we assume that the time between periods is very small. As the interval between offers and counteroffers shortens and shrinks to zero, the alternating-offer model has a unique limiting subgame perfect equilibrium (SPE), which approximates the Nash bargaining solution to the bargaining problem (see Binmore, Rubinstein and Wolinsky [9]). Hence, the SPE shares are given by $\left(x_{1}^{*}, x_{2}^{*}\right)=\operatorname{argmax}_{\left(x_{1}^{*}, x_{2}^{*}\right) \in X}\left(u_{1}\right)^{\alpha}\left(u_{2}\right)^{1-\alpha}$, where the status quo payoffs are zero and the parameter $\alpha, 0<\alpha<1$, is equal to $r_{2} /\left(r_{1}+r_{2}\right)$ and can be interpreted as player 1's bargaining power. A simple calculation leads to:

$$
x_{1}^{*}=\frac{1+\gamma+2 \gamma \alpha-\sqrt{1+2 \gamma-(4-\gamma) \gamma \alpha^{2}}}{2 \gamma(1+\alpha)} \text { and } x_{2}^{*}=1-x_{1}^{*}
$$

Then, the SPE payoffs for player 1 and player 2 are equal to:

$$
\begin{aligned}
u_{1}^{*}(\alpha) & =\frac{\alpha}{2 \gamma(1+\alpha)^{2}}\left(1+\gamma(2+(4-\gamma) \alpha)-(1-\gamma) \sqrt{1+2 \gamma-(4-\gamma) \gamma \alpha^{2}}\right) \\
u_{2}^{*}(\alpha) & =\frac{-1+\gamma+\sqrt{1+2 \gamma-(4-\gamma) \gamma \alpha^{2}}}{2 \gamma(1+\alpha)}
\end{aligned}
$$

Of course, we have that $\partial x_{1}^{*} / \partial \alpha>0$ and $\partial u_{1}^{*} / \partial \alpha>0$. In addition, $\partial x_{1}^{*} / \partial \gamma>0$ if and only if $\alpha<1 / 2$. More interestingly, we find that $\partial u_{1}^{*} / \partial \gamma>0$ if and only if $\alpha<1 / 2$ and $\partial u_{2}^{*} / \partial \gamma>0$ if and only if $\alpha>1 / 2$. So the equilibrium share of player 2 (and his payoff) is increasing with the relative concerns of player 1 when player 1 has more bargaining power than player 2 (i.e., when $\alpha>1 / 2$ or $\left.r_{2}>r_{1}\right)$.

Proposition 1. Consider the alternating-offer bargaining game with complete information and where only player 1 has relative concerns. An increase of player 1's relative concerns increases player 2's SPE payoff if and only if player 1 is more patient than player 2.

\footnotetext{
${ }^{3}$ This utility function can be interpreted as a special case of Fehr and Schmidt's [8] model of inequality aversion when compassion is as strong as envy and there is no pride. We discuss this model in the conclusion.

${ }^{4}$ We limit the analysis to the case where only one player is not purely selfish in order to obtain closed-form solutions. However, this case already captures the driving force for introducing relative concerns into the bargaining and can help us to understand what would happen if both players would dislike payoff inequality.
} 
The intuition behind this proposition is as follows. Whether an increase in $\gamma$ is beneficial or not for player 2 depends on his relative bargaining power. When player 2 is weaker than his opponent (or less patient), then he prefers to face an opponent who cares more about relative concerns, since this opponent will claim a more equitable allocation. However, once player 2 becomes stronger than his opponent, then facing a party who cares more about equity will reduce player 2's share of the pie. In other words, an increase of player 1's relative concerns will decrease (increase) player 2's "real bargaining power" when player 2 is more (less) patient than player 1 . To conclude, facing an opponent having stronger relative concerns only hurts the bargainer when she is stronger than her opponent.

\section{Maximum Delay in Reaching an Agreement}

Both the asymmetric Nash bargaining solution and Rubinstein's model predict efficient outcomes of the bargaining process. In particular, agreement is reached immediately. ${ }^{5}$ This is not the case once we introduce incomplete information into the bargaining, in which the first rounds of the negotiation are used for information transmission between the two negotiators.

We now suppose that both players have private information. Neither player knows the impatience (or discount rate) of the other party. It is common knowledge player 1's discount rate lies in the range $\left[\underline{r}_{1}, \bar{r}_{1}\right]$, where $0<\underline{r}_{1} \leq \bar{r}_{1}$, and that player 2 's discount rate lies in the range $\left[\underline{r}_{2}, \bar{r}_{2}\right]$, where $0<\underline{r}_{2} \leq \bar{r}_{2}$. The discount rates $\underline{r}_{i}$ and $\bar{r}_{i}$ identify the most patient and most impatient types, respectively. The types are independently drawn from the set $\left[\underline{r}_{i}, \bar{r}_{i}\right]$ according to the probability distribution $p_{i}$, for $i=1,2$. This uncertainty implies bounds on player 1's bargaining power which are denoted by $\underline{\alpha}=\underline{r}_{2} /\left(\bar{r}_{1}+\underline{r}_{2}\right)$ and $\bar{\alpha}=\bar{r}_{2} /\left(\underline{r}_{1}+\bar{r}_{2}\right)$. Watson [12] has characterized the set of perfect Bayesian equilibrium (PBE) payoffs which may arise in Rubinstein's alternating-offer bargaining game and constructed bounds (which are met) on the agreements that may be made. The bounds and the PBE payoffs set are determined by the range of incomplete information, and are easy to compute because they correspond to the SPE payoffs of two bargaining games with complete information. These two games are defined by matching one player's most impatient type with the opponent's most patient type.

Lemma 1. Consider the alternating-offer bargaining game with incomplete information in which the distributions $p_{1}$ and $p_{2}$ are common knowledge, and in which the period length shrinks to zero. For any perfect Bayesian equilibrium (PBE), the payoff of player 1 belongs to $\left[u_{1}^{*}(\underline{\alpha}), u_{1}^{*}(\bar{\alpha})\right]$ and the payoff of player 2 belongs to $\left[u_{2}^{*}(\bar{\alpha}), u_{2}^{*}(\underline{\alpha})\right]$.

In Lemma $1, u_{1}^{*}(\underline{\alpha})$ and $u_{2}^{*}(\underline{\alpha})$ denote, respectively, the SPE utility of player 1 and the SPE utility of player 2 of the complete information game, when it is common knowledge that player 1's bargaining power is $\alpha=\underline{\alpha}$. Since we allow for general distributions over types, multiplicity of PBE is not an exception even when the game is almost with complete information. For instance, Watson [12] has examined Rubinstein's bargaining games in which with high probability a player's discount rate is close

\footnotetext{
${ }^{5}$ Multiple SPE arise and agreements may be delayed (even with complete information) if at least one player has the possibility to reduce the value of the cake after her own proposal is rejected (see Avery and Zemsky [10]). Houba and Wen [11] have shown that in a bargaining model with a disagreement game between offers and counteroffers, it may not be Pareto efficient to reach an immediate agreement. Another source for agreements reached with delay is incomplete information.
} 
to a certain value, yet there is a slight chance that the player's discount rate is much higher or much lower. Watson has shown that the set of equilibrium payoffs does not converge to that of the complete information, despite that the game converges to one of complete information. More precisely, the set converges from above but not from below in the sense that a player cannot gain if there is a slight chance that she is very patient, yet she can suffer if there is a slight chance that she is impatient. ${ }^{6}$

The bargaining game may involve delay, but not perpetual disagreement, in equilibrium. ${ }^{7}$ Delay is positively related to the distance between the discount rates of the most and least patient types of the players. If the range of types is reduced, then this leads to a smaller range of possible payoffs and less delay. Delay can even occur when the game is close to one of complete information (as the type distributions converge to point mass distributions). We propose to analyze the maximum delay time in reaching an agreement. It is simply the minimum between the maximum real time player 1 would spend bargaining and the maximum real time player 2 would spend bargaining. This measure is, on average, a good proxy for actual delay in reaching an agreement. ${ }^{8}$ The maximum real time player 1 (player 2) would spend bargaining is the time $D^{1}\left(D^{2}\right)$ such that player 1 (player 2) is indifferent between getting the lower bound PBE payoff at time 0 , and getting the upper bound PBE payoff at time $D^{1}\left(D^{2}\right)$. In the Appendix we derive the expression for the maximum delay in equilibrium which shows that an agreement is reached in finite time and that delay time equals zero as incomplete information vanishes (in that $\bar{r}_{i}$ and $\underline{r}_{i}$ converge). ${ }^{9}$

Formally, delay in reaching an agreement is given by $D(\gamma)=\min \left\{D^{1}(\gamma), D^{2}(\gamma)\right\}$, where

$$
\begin{aligned}
D^{1}(\gamma)= & -\frac{1}{\underline{r}_{1}} \log \left[\frac{\underline{r}_{2}}{\bar{r}_{2}}\left(\frac{\underline{r}_{1}+2 \bar{r}_{2}}{\bar{r}_{1}+2 \underline{r}_{2}}\right)^{2} .\right. \\
& \left.\frac{(1+2 \gamma) \bar{r}_{1}+(1+(6-\gamma) \gamma) \underline{r}_{2}-(1-\gamma) \sqrt{(1+2 \gamma)\left(\bar{r}_{1}^{2}+2 \bar{r}_{1} \underline{r}_{2}\right)+(1-\gamma)^{2} \underline{r}_{2}^{2}}}{(1+2 \gamma) \underline{r}_{1}+(1+(6-\gamma) \gamma) \bar{r}_{2}-(1-\gamma) \sqrt{(1+2 \gamma)\left(\underline{r}_{1}^{2}+2 \underline{r}_{1} \bar{r}_{2}\right)+(1-\gamma)^{2} \bar{r}_{2}^{2}}}\right]
\end{aligned}
$$

is the maximum real time player 1 would spend negotiating, and

$$
D^{2}(\gamma)=-\frac{1}{\underline{r}_{2}} \log \left[\frac{\bar{r}_{1}+2 \underline{r}_{2}}{\underline{r}_{1}+2 \bar{r}_{2}} \frac{\left(\underline{r}_{1}+\bar{r}_{2}\right)(1-\gamma)-\sqrt{(1+2 \gamma)\left(\underline{r}_{1}^{2}+2 \underline{r}_{1} \bar{r}_{2}\right)+(1-\gamma)^{2} \bar{r}_{2}^{2}}}{\left(\bar{r}_{1}+\underline{r}_{2}\right)(1-\gamma)-\sqrt{(1+2 \gamma)\left(\bar{r}_{1}^{2}+2 \bar{r}_{1} \underline{r}_{2}\right)+(1-\gamma)^{2} \underline{r}_{2}^{2}}}\right]
$$

is the maximum real time player 2 would spend negotiating. In fact, $D^{1}(\gamma)$ is the maximum real time player 1 would spend negotiating if it were of the most patient type. Similarly, $D^{2}(\gamma)$ is the maximum real time player 2 would spend negotiating if it were of the most patient type. So, $D^{1}(\gamma)$ and $D^{2}(\gamma)$ are the upper bounds on the maximum time player 1 of type $r_{1}$ and player 2 of type $r_{2}$ would spend negotiating. Since $D^{1}(\gamma)$ and $D^{2}(\gamma)$ are positive, finite numbers, the maximum real delay in reaching an agreement is finite and converges to zero as $\underline{r}_{i}$ and $\bar{r}_{i}$ become close. Taking the derivatives with respect to $\gamma$, we get that $\partial D^{1}(\gamma) / \partial \gamma<0$ and $\partial D^{2}(\gamma) / \partial \gamma<0$.

\footnotetext{
${ }^{6}$ The limiting set of equilibrium payoffs is defined by each player's greatest possible discount rate and the limiting discount rates; the players' lowest possible discount rates do not play a role. That is, a slight chance of being a patient type can't help a player, whereas a slight chance of being impatient can certainly hurt.

${ }^{7}$ Watson [12] has constructed equilibria with delay in which the types of each player behave identically (no information is revealed in equilibrium), players use pure strategies, and players make non-serious offers until some appointed date.

${ }^{8} \mathrm{Cai}[13]$ has also analysed the maximum number of delay periods but in a multilateral bargaining.

${ }^{9}$ When the range of types converges to 0 , the game reduces to one of complete information and the agreement is reached without delay.
} 
Proposition 2. Consider the alternating-offer bargaining game with incomplete information and where only player 1 has relative concerns. An increase of player 1's relative concerns decreases both the maximum real time player 1 would spend negotiating and the maximum real time player 2 would spend negotiating.

The intuition behind this proposition is as follows. An increase of player 1's relative concerns ( $\gamma$ increases) expands the payoff set or range of possible payoffs for player 1 . Hence, it increases the scope for potential delay in reaching an agreement since more time may be needed for screening the private information. However, there is a second effect at play. When $\gamma$ increases, player 1 is more inclined to concede, and to agree more rapidly on a smaller share of the surplus than before, since it is compensated by the increased utility due to less envy and compassion. This second effect dominates the first one. Hence, $\partial D^{1}(\gamma) / \partial \gamma<0$. For player 2 who is purely selfish but faces an opponent who dislikes payoff inequality, an increase of player 1's relative concerns reduces the range of possible payoffs for player 2 to shares closer to the equitable division. Hence, $\partial D^{2}(\gamma) / \partial \gamma<0$. Since the delay in reaching an agreement, $D(\gamma)$, is equal to $\min \left\{D^{1}(\gamma), D^{2}(\gamma)\right\}$, we conclude that an increase of player 1 's relative concerns will decrease the maximum real delay in reaching an agreement.

Table 1. Maximum delay in reaching an agreement.

\begin{tabular}{ccccccccccc}
\hline \multicolumn{1}{c}{$\mathbf{1}$} & \multicolumn{1}{c}{$\mathbf{3} / \mathbf{4}$} & \multicolumn{3}{c}{$\mathbf{1 / 2}$} & \multicolumn{3}{c}{$\mathbf{1 / 4}$} & \multicolumn{3}{c}{$\mathbf{1 / 0}$} \\
\hline$\underline{r}$ & $D^{1}$ & $D^{2}$ & $D^{1}$ & $D^{2}$ & $D^{1}$ & $D^{2}$ & $D^{1}$ & $D^{2}$ & $D^{1}$ & $D^{2}$ \\
\cline { 2 - 11 } 0.18 & 0 & 0 & 0 & 0 & 0 & 0 & 0 & 0 & 0 & 0 \\
0.17 & 0 & 0 & 0 & 0 & 0 & 0 & 0 & 0 & 0 & 0 \\
0.16 & 0 & 0 & 1 & 1 & 1 & 1 & 1 & 1 & 1 & 1 \\
0.15 & 1 & 1 & 1 & 1 & 1 & 1 & 1 & 1 & 2 & 2 \\
0.14 & 2 & 2 & 2 & 2 & 2 & 2 & 2 & 2 & 3 & 3 \\
0.13 & 2 & 2 & 3 & 3 & 3 & 3 & 3 & 3 & 4 & 4 \\
0.12 & 3 & 3 & 4 & 4 & 4 & 4 & 5 & 5 & 5 & 5 \\
0.11 & 5 & 4 & 5 & 5 & 6 & 5 & 6 & 6 & 7 & 7 \\
0.10 & 6 & 6 & 7 & 6 & 7 & 7 & 8 & 8 & 9 & 9 \\
0.09 & 8 & 7 & 9 & 8 & 9 & 9 & 10 & 10 & 11 & 11 \\
0.08 & 10 & 10 & 11 & 11 & 12 & 12 & 14 & 14 & 15 & 14 \\
0.07 & 14 & 13 & 15 & 14 & 16 & 16 & 18 & 18 & 19 & 19 \\
0.06 & 19 & 17 & 20 & 19 & 22 & 21 & 24 & 24 & 25 & 25 \\
0.05 & 26 & 23 & 28 & 26 & 30 & 29 & 33 & 32 & 35 & 35 \\
0.04 & 38 & 32 & 41 & 37 & 44 & 42 & 47 & 47 & 50 & 50 \\
\hline
\end{tabular}

We now illustrate our main results by means of an example. Suppose that both players have the same bounds on their discount rates: $\underline{r}_{1}=\underline{r}_{2}=\underline{r}, \bar{r}_{1}=\bar{r}_{2}=\bar{r}, \bar{r}=0.36-\underline{r}$ with $\underline{r} \in[0.04,0.18]$. Table 1 gives the integer part of the maximum delay for the different values of the parameter $\gamma$. We can interpret $r_{i}$ as the annual discount rate and the numbers in Table 1 as the maximum number of days needed to reach an agreement. Indeed, the integer part of the maximum delays for $\Delta=1 / 365$ are exactly the 
numbers in Table $1 .{ }^{10}$ We observe that (i) the real delay time in reaching an agreement is not negligible: many bargaining rounds may be needed in equilibrium before an agreement is reached; (ii) $D^{1}$ and $D^{2}$ are decreasing with $\gamma$; (iii) $D^{1}$ and $D^{2}$ are increasing with the amount of private information $\left|\bar{r}_{i}-\underline{r}_{i}\right|$; (iv) the maximum delay $D(\gamma)=\min \left\{D^{1}(\gamma), D^{2}(\gamma)\right\}$ is decreasing with $\gamma$; (v) $D^{1} \geq D^{2}$. Results (i)-(iv) hold in general.

\section{Concluding Discussion}

We have considered Rubinstein's alternating-offer bargaining model with two-sided incomplete information and we have investigated the effects of having relative concerns on the agreement and the delay in reaching this agreement. We have shown that an increase of relative concerns will decrease the delay in reaching an agreement.

Fehr and Schmidt [8] have proposed an alternative model of inequality aversion: $U_{i}\left(x_{1}, x_{2}\right)=x_{i}-$ $\gamma \max \left\{x_{j}-x_{i}, 0\right\}-\beta \max \left\{x_{i}-x_{j}, 0\right\}$, where they assume that $\gamma \geq \beta$ and that $\beta$ satisfies $1>\beta \geq 0$. The parameter $\gamma$ captures the envy. If the parameter $\beta$ is positive, then it captures the compassion. But if $\beta$ is negative, then it captures the pride. One can see that if $\beta$ is negative and equal to $-\gamma$, then the Fehr and Schmidt's model reduces to the utility function $U_{i}\left(x_{1}, x_{2}\right)=x_{i}-\gamma\left(x_{j}-x_{i}\right)$ where pride is as strong as envy and there is no compassion. It can be shown that, as long as pride is as strong as envy and there is no compassion, the bargaining outcome does not depend on the parameter $\gamma$. However, if $\beta$ is positive and equal to $\gamma$ (i.e., compassion is as strong as envy and there is no pride), then the Fehr and Schmidt's model reverts to Bolton and Ockenfels' model of inequality aversion and delay in reaching an agreement decreases as relative concerns increase. ${ }^{11}$

We have limited the analysis to the case where only one player is not purely selfish. We now provide some insights about what would happen under complete information if both players had relative concerns captured by Fehr and Schmidt's [8] model of inequality aversion with $\gamma \geq \beta$ and $1 / 2>\beta \geq 0 .{ }^{12}$ For $\alpha<(1-2 \beta) /(2(1-\beta+\gamma)) \leq 1 / 2$, the SPE payoffs for player 1 and player 2 are equal to

$$
U_{1}^{*}(\alpha, \gamma, \beta)=\alpha \frac{1-\beta+\gamma}{1-2 \beta} \text { and } U_{2}^{*}(\alpha, \gamma, \beta)=(1-\alpha) \frac{1-\beta+\gamma}{1+2 \gamma} .
$$

Hence, when player 1 is sufficiently less patient than player 2, an increase of player 1's envy $\gamma$ decreases player 2's SPE payoff. In addition, an increase of player 1's envy $\gamma$ increases player 1's SPE payoff. Notice that an increase of player 2's compassion $\beta$ increases (decreases) the payoff of player 1 (player 2). For $\alpha>(1+2 \gamma) /(2(1-\beta+\gamma)) \geq 1 / 2$, the SPE payoffs for player 1 and player 2 are equal to

$$
U_{1}^{*}(\alpha, \gamma, \beta)=\alpha \frac{1-\beta+\gamma}{1+2 \gamma} \text { and } U_{2}^{*}(\alpha, \gamma, \beta)=(1-\alpha) \frac{1-\beta+\gamma}{1-2 \beta} .
$$

\footnotetext{
${ }^{10}$ The data in Table 1 seem consistent with delays reported in Cramton and Tracy [14].

${ }^{11}$ De Bruyn and Bolton [2] have shown that the ERC model provides satisfactory fit for sequential bargaining game data along several dimensions (first-offer behavior, rejection behavior, disadvantageous counteroffers, ...) and that the estimates of fairness preferences obtained in one bargaining situation are indicative of bargainer behavior in other situations where strategic parameters such as time cost, stake and bargaining length differ.

${ }^{12}$ The condition $1 / 2>\beta \geq 0$ on the compassion parameter guarantees the existence of an interior solution to the bargaining problem.
} 
Closely related to Proposition 1, we obtain that an increase of player 1's compassion $\beta$ increases player 2 's SPE payoff if player 1 is sufficiently more patient than player 2 . Once both players have private information, based on the intuition provided by the one sided relative concerns case, we expect that delay will be even more reduced since both players are more inclined to concede and agree rapidly on a more equitable allocation of the surplus. ${ }^{13}$

\section{Acknowledgements}

Vincent Vannetelbosch and Ana Mauleon are, respectively, Senior Research Associate and Research Associate of the National Fund for Scientific Research (FNRS). Financial support from the Spanish Ministry of Economy and Competition under the project ECO2012-35820 is gratefully acknowledged.

\section{Conflict of Interest}

The authors declare no conflict of interest.

\section{References}

1. Rubinstein, A. Perfect equilibrium in a bargaining model. Econometrica 1982, 50, 97-109.

2. De Bruyn, A.; Bolton, G.E. Estimating the influence of fairness on bargaining behavior. Manag. Sci. 2008, 54, 1774-1791.

3. Sobel, J. Interdependent preferences and reciprocity. J. Econ. Lit. 2005, 43, 347-391.

4. Hopkins, E. Inequality, happiness and relative concerns: What actually is their relationship? $J$. Econ. Inequal. 2008, 6, 351-372.

5. Brown, G.D.; Gardner, J.; Oswald, A.J.; Qian, J. Does wage rank affect employees' well-being? Ind. Relat. 2008, 47, 355-389.

6. Clark, A.E.; Oswald, A.J. Satisfaction and comparison income. J. Public Econ. 1996, 61, 359-381.

7. Bolton, G.E.; Ockenfels, A. ERC: A theory of equity, reciprocity, and competition. Am. Econ. Rev. 2000, 90, 166-193.

8. Fehr, E.; Schmidt, K. A theory of fairness, competition, and cooperation. Q. J. Econ. 1999, 114, 817-868.

9. Binmore, K.G.; Rubinstein, A.; Wolinsky, A. The Nash bargaining solution in economic modelling. Rand J. Econ. 1986, 17, 176-188.

10. Avery, C.; Zemsky, P.B. Money burning and multiple equilibria in bargaining. Games Econ. Behav. 1994, 7, 154-168.

11. Houba, H.; Wen, Q. Extreme equilibria in the negotiation model with different time preferences. Games Econ. Behav. 2011, 73, 507-516.

12. Watson, J. Alternating-offer bargaining with two-sided incomplete information. Rev. Econ. Studies 1998, 65, 573-594.

\footnotetext{
${ }^{13}$ Delays caused by private information about players' discount rates are reduced when relative concerns are introduced. However, if players' relative concerns would not be common knowledge, then this new source of incomplete information could lead to more delay since more time may be needed for screening the players' types.
} 
13. Cai, H. Inefficient Markov perfect equilibria in multilateral bargaining. Econ. Theory 2003, 22, 583-606.

14. Cramton, P.C.; Tracy, J.S. The determinants of U.S. labor disputes. J. Labor Econ. 1994, 12, 180-209.

15. Mauleon, A.; Vannetelbosch, V. Strategic union delegation and strike activity. Can. J. Econ. 2005, $38,149-173$.

\section{Appendix}

The negotiation goes as in Rubinstein's [1] alternating-offer bargaining model. Player 1 and player 2 have time preferences with constant discount factors $\delta_{1} \in(0,1)$ and $\delta_{2} \in(0,1)$, respectively. For any bargaining which leads to an agreement $\left(x_{1}, x_{2}\right)$ at period $n, \delta_{1}^{n} u_{1}\left(x_{1}, x_{2}\right)$ and $\delta_{2}^{n} u_{2}\left(x_{1}, x_{2}\right)$ are, respectively, player 1's payoff and player 2's payoff. For any bargaining which leads to perpetual disagreement, disagreement payoffs are set to zero. As in Binmore, Rubinstein and Wolinsky [9], the SPE outcome is such that $u_{1}\left(x_{12}, x_{22}\right)=\delta_{1} u_{1}\left(x_{11}, x_{21}\right)$ and $u_{2}\left(x_{11}, x_{21}\right)=\delta_{2} u_{2}\left(x_{12}, x_{22}\right)$, where $\left(x_{11}, x_{21}\right)$ is the SPE outcome if player 1 makes the first offer, and $\left(x_{12}, x_{22}\right)$ is the SPE outcome if player 2 makes the first offer. Since player 1 makes the first offer, the SPE shares are given by

$$
\begin{aligned}
x_{1}^{*}\left(\delta_{1}, \delta_{2}\right)= & \frac{1}{2\left(1-\delta_{1} \delta_{2}^{2}\right) \gamma}\left[2 \gamma+\delta_{2}\left(2-\left(1+\delta_{1} \delta_{2}\right)(1+\gamma)\right)-\right. \\
& \left.\delta_{2} \sqrt{\left(1+\delta_{1}^{2} \delta_{2}^{2}\right)(1+2 \gamma)-2 \delta_{1} \delta_{2}(1-\gamma)^{2}-\delta_{1}\left(1+\delta_{2}^{2}\right)(4-\gamma) \gamma}\right] \\
x_{2}^{*}\left(\delta_{1}, \delta_{2}\right)= & \frac{1}{2\left(1-\delta_{1} \delta_{2}^{2}\right) \gamma}\left[\delta_{2}\left(1-\delta_{1} \delta_{2}\right)(-1+\gamma)+\right. \\
& \left.\delta_{2} \sqrt{\left(1+\delta_{1}^{2} \delta_{2}^{2}\right)(1+2 \gamma)-2 \delta_{1} \delta_{2}(1-\gamma)^{2}-\delta_{1}\left(1+\delta_{2}^{2}\right)(4-\gamma) \gamma}\right] \\
= & u_{2}^{*}\left(\delta_{1}, \delta_{2}\right)
\end{aligned}
$$

and player 1's SPE payoff is given by

$$
\begin{aligned}
u_{1}^{*}\left(\delta_{1}, \delta_{2}\right)= & \frac{1-\delta_{2}}{4\left(1-\delta_{1} \delta_{2}^{2}\right)^{2} \gamma}\left[\left(1-\delta_{1} \delta_{2}^{3}\right) \gamma(4-\gamma)+\delta_{2}\left(1-\delta_{1} \delta_{2}\right)\left(2+\gamma^{2}\right)-\right. \\
& \left.2(1-\gamma) \delta_{2} \sqrt{\left(1+\delta_{1}^{2} \delta_{2}^{2}\right)(1+2 \gamma)-2 \delta_{1} \delta_{2}(1-\gamma)^{2}-\delta_{1}\left(1+\delta_{2}^{2}\right)(4-\gamma) \gamma}\right] .
\end{aligned}
$$

Suppose now that the players have private information. They are uncertain about each others' discount factors. Player $i$ 's discount factor lies in the range $\left[\underline{\delta}_{i}, \bar{\delta}_{i}\right]$, where $0<\underline{\delta}_{i} \leq \bar{\delta}_{i}<1$. The types are independently drawn from the interval $\left[\underline{\delta}_{i}, \bar{\delta}_{i}\right]$ according to the probability distribution $p_{i}$, for $i=1,2$.

Lemma A1. Consider the alternating-offer bargaining game with two-sided incomplete information in which the distributions $p_{1}$ and $p_{2}$ are common knowledge, and in which the period length shrinks to zero. For any perfect Bayesian equilibria (PBE), the payoff of player 1 belongs to $\left[u_{1}^{*}\left(\underline{\delta}_{1}, \bar{\delta}_{2}\right), u_{1}^{*}\left(\bar{\delta}_{1}, \underline{\delta}_{2}\right)\right]$ and the payoff of player 2 belongs to $\left[u_{2}^{*}\left(\bar{\delta}_{1}, \underline{\delta}_{2}\right), u_{2}^{*}\left(\underline{\delta}_{1}, \bar{\delta}_{2}\right)\right]$. 
This lemma is not a direct corollary to Watson [12] Theorem 1, because Watson's work focuses on linear preferences, but the analysis can be modified to handle the present case (see e.g., Mauleon and Vannetelbosch [15]). Since we allow for general probability distributions over discount factors, multiplicity of PBE is not an exception.

The maximum number of bargaining periods player 1 would spend negotiating, $I\left(m^{1}(\gamma)\right)$, is given by $u_{1}^{*}\left(\underline{\delta}_{1}, \bar{\delta}_{2}\right)=\left(\bar{\delta}_{1}\right)^{m^{1}(\gamma)} u_{1}^{*}\left(\bar{\delta}_{1}, \underline{\delta}_{2}\right)$, from which we obtain $m^{1}(\gamma)=$ $\left(\log \left(\bar{\delta}_{1}\right)\right)^{-1} \log \left[u_{1}^{*}\left(\underline{\delta}_{1}, \bar{\delta}_{2}\right) / u_{1}^{*}\left(\bar{\delta}_{1}, \underline{\delta}_{2}\right)\right]$. Notice that $I\left(m^{1}(\gamma)\right)$ is simply the integer part of $m^{1}(\gamma)$. We express the players' discount factors in terms of discount rates, $r_{1}$ and $r_{2}$, and the length of the bargaining period, $\Delta$, according to the formula $\delta_{i}=\exp \left(-r_{i} \Delta\right)$. Note that $\bar{r}_{i} \geq \underline{r}_{i}$ since greater patience implies a lower discount rate. As $\Delta$ approaches zero, using l'Hopital's rule we obtain that

$$
\begin{aligned}
D^{1}(\gamma)= & \lim _{\Delta \rightarrow 0}\left(m^{1}(\gamma) \cdot \Delta\right)=-\frac{1}{\underline{r}_{1}} \log \left[\frac{\underline{r}_{2}}{\bar{r}_{2}}\left(\frac{\underline{r}_{1}+2 \bar{r}_{2}}{\bar{r}_{1}+2 \underline{r}_{2}}\right)^{2} .\right. \\
& \left.\frac{(1+2 \gamma) \bar{r}_{1}+(1+(6-\gamma) \gamma) \underline{r}_{2}-(1-\gamma) \sqrt{(1+2 \gamma)\left(\bar{r}_{1}^{2}+2 \bar{r}_{1} \underline{r}_{2}\right)+(1-\gamma)^{2} \underline{r}_{2}^{2}}}{(1+2 \gamma) \underline{r}_{1}+(1+(6-\gamma) \gamma) \bar{r}_{2}-(1-\gamma) \sqrt{(1+2 \gamma)\left(\underline{r}_{1}^{2}+2 \underline{r}_{1} \bar{r}_{2}\right)+(1-\gamma)^{2} \bar{r}_{2}^{2}}}\right]
\end{aligned}
$$

which is a positive, finite number. Notice that $D^{1}(\gamma)$ converges to zero as $\underline{r}_{i}$ and $\bar{r}_{i}$ become close. Taking the derivative with respect to $\gamma$, we obtain that $\partial D^{1}(\gamma) / \partial \gamma<0$.

The maximum number of bargaining periods player 2 would spend negotiating, $I\left(m^{2}(\gamma)\right)$, is given by $u_{2}^{*}\left(\bar{\delta}_{1}, \underline{\delta}_{2}\right)=\left(\bar{\delta}_{2}\right)^{m^{2}(\gamma)} u_{2}^{*}\left(\underline{\delta}_{1}, \bar{\delta}_{2}\right)$, from which we obtain $m^{2}(\gamma)=\left(\log \left(\bar{\delta}_{2}\right)\right)^{-1} \log \left[u_{2}^{*}\left(\bar{\delta}_{1}, \underline{\delta}_{2}\right) / u_{2}^{*}\left(\underline{\delta}_{1}, \bar{\delta}_{2}\right)\right]$, and as $\Delta$ approaches zero,

$$
\begin{aligned}
D^{2}(\gamma) & =\lim _{\Delta \rightarrow 0}\left(m^{2}(\gamma) \cdot \Delta\right) \\
& =-\frac{1}{\underline{r}_{2}} \log \left[\frac{\bar{r}_{1}+2 \underline{r}_{2}}{\underline{r}_{1}+2 \bar{r}_{2}} \frac{\left(\underline{r}_{1}+\bar{r}_{2}\right)(1-\gamma)-\sqrt{(1+2 \gamma)\left(\underline{r}_{1}^{2}+2 \underline{r}_{1} \bar{r}_{2}\right)+(1-\gamma)^{2} \bar{r}_{2}^{2}}}{\left(\bar{r}_{1}+\underline{r}_{2}\right)(1-\gamma)-\sqrt{(1+2 \gamma)\left(\bar{r}_{1}^{2}+2 \bar{r}_{1} \underline{r}_{2}\right)+(1-\gamma)^{2} \underline{r}_{2}^{2}}}\right]
\end{aligned}
$$

which is a positive, finite number. Taking the derivative with respect to $\gamma$, we obtain that $\partial D^{2}(\gamma) / \partial \gamma<0$. The maximum real delay time before reaching an agreement is given by $D(\gamma)=\min \left\{D^{1}(\gamma), D^{2}(\gamma)\right\}$

(c) 2013 by the authors; licensee MDPI, Basel, Switzerland. This article is an open access article distributed under the terms and conditions of the Creative Commons Attribution license (http://creativecommons.org/licenses/by/3.0/). 